\title{
PENERIMAAN GAME INSTRUKSIONAL DRAGONBOX ALGEBRA 12+ PADA PEMBELAJARAN ALJABAR BERDASARKAN TEORI TECHNOLOGY ACCEPTANCE MODEL (TAM)
}

\author{
Riana Teofani ${ }^{1}$, Jefri Marzal ${ }^{2}$ Hendra Sofyan $^{3}$ \\ 1,2,3 Jl. Raden Mattaher No.16 Universitas Jambi, Jambi, Indonesia \\ rianateofani15@gmail.com
}

\begin{abstract}
This study to determine the factors influence student acceptance of the mathematics learning game DragonBox Algebra $12+$ in algebra learning. The acceptance factor is usefulness, Perceived ease of use, personal innovativeness in the domain of IT, attitude, and acceptance. Where this acceptance factor can be taken into consideration whether or not the game Dragonbox algebra $12+$ is used in algebra learning. This research uses quantitative methods with survey research and explanatory research design. Based on data analysis, the results are obtained (1) Perceived ease of use has positive effect on the perceive usefulness of using the DragonBox Algebra 12+ in mathematics learning. (2) Perceived ease of use has a positive influence on students' attitudes in using the DragonBox Algebra 12+. (3) perceive usefulness has positive influence on students' attitudes in using the DragonBox Algebra 12+ (4) perceive usefulness has positive effect on the acceptance of the DragonBox Algebra 12+ in learning mathematics. (5) Personal innovativeness in the domain of IT has positive influence on attitudes formed by students in the learning game DragonBox Algebra 12+ (6) attitudes toward the learning game DragonBox Algebra 12+ have a positive influence on the acceptance of the DragonBox Algebra 12+ in the mathematics learning.
\end{abstract}

Keyword:Technology Acceptance Model, Learning Game, DragonBox Algebra 12+, Algebra Acceptance of education technology

\begin{abstract}
Abstrak
Penelitian ini bertujuan untuk mengetahui faktor yang mempengaruhi penerimaan siswa terhadap game pembelajaran matematika DragonBox Algebra 12+ di dalam pembelajaran aljabar . Faktor penerimaan yang dimaksud adalah persepsi manfaat penggunaan, persepsi kemudahan penggunaan, Personal innovativeness in the domain of IT, attitude, dan acceptance. Dimana faktor penerimaan ini dapat dijadikan bahan pertimbangan layak atau tidak layaknya game dragonbox algebra $12+$ di gunakan dalam pembelajaran aljabar. Penelitian ini menggunakan metode kuantitatif dengan jenis penelitian survey dan desain penelitian ekplanatif (explanatory). Berdasarkan analisis data diperoleh hasil (1) Persepsi kemudahan penggunaan memiliki pengaruh positif terhadap manfaat penggunaan game pembelajaran DragonBox Algebra 12+ di dalam pembelajaran matematika. (2) Persepsi kemudahan penggunaan memiliki pengaruh positif terhadap sikap siswa dalam penggunaan game pembelajaran DragonBox Algebra 12+. (3) Persepsi manfaat penggunaan memiliki pengaruh positif terhadap sikap siswa dalam penggunaan game pembelajaran DragonBox Algebra 12+. (4) Persepsi manfaat penggunaan memiliki pengaruh positif terhadap penerimaan game pembelajaran DragonBox Algebra 12+ dalam pembelajaran matematika. (5) Personal innovativeness in the domain of IT memiliki pengaruh yang positif terhadap terhadap sikap yang dibentuk siswa pada game pembelajaran DragonBox Algebra 12+ (6) sikap terhadap game pembelajaran DragonBox Algebra 12+ memiliki pengaruh positif terhadap Penerimaan geme pembelajaran DragonBox Algebra 12+ dalam pembelajaran matematika.
\end{abstract}

Kata Kunci: Technology Acceptance Model, Game Pembelajaran, DragonBox Algebra 12+, Aljabar Penerimaan Teknologi Pendidikan

\section{PENDAHULUAN}

Peran teknologi di dalam pendidikan diharapkan dapat memberi inovasi yang mampu mengubah pembelajaran konvesional menjadi pembelajaran nonkonvensional. Pembelajaran konvensional diyakini sebagai sistem yang tidak efisien lagi, dimana kemampuan otak, kecerdasan, dan kreatifitas 
siswa saat ini telah berkembang ke arah yang lebih modern. Adanya suasana baru yang diberikan oleh teknologi membuat pendidik manaruh harapan besar pada teknologi untuk dapat memecahkan semua masalah di dalam pendidikan. Teknologi dapat dijadikan sebagai media pembelajran agar dapat menarik minat serta membantu siswa dalam memahami isi dari pembelajaran tersebut.

Pendidik Indonesia masih belum banyak yang memanfaatkan game pembelajaran sebagai media pembelajaran. Kondisi ini berbeda dengan beberapa sekolah modern di Negara maju, Salah satunya Tolsia High school dimana mereka menggunakan aplikasi DragonBox Algebra $12+$ dalam proses pembelajarannya matematika. Berdasarkan laporan Tawnya dalam (Siew et al., 2016) yang merupakan seorang guru matematika di sekolah tersebut mengatakan, dalam penggunaan aplikasi ini siswanya dapat melakukan kerja sama yang baik dengan rekan mereka, menimbulkan rasa yang menyenangkan, serta visual dari DragonBox Algebra 12+ ini pun juga terlihat bagus dan menarik (Dolonen \& Kluge, 2015). Pencipta game ini mengklaim bahwa DragonBox Algebra 12+ dirancang sebagai media pembelajaran agar pembelajaran aljabar lebih cepat dan mudah dalam penyampaiannya. Konsep game ini menggabungkan antara kesenangan yang dicari anak di dalam gadget dengan pembelajaran yang mereka butuhkan. Sehingga seharusnya game ini juga dapat digunakan pada proses pembelajaran matematika di indonesia.

menerapkan game pembelajaran DragonBox Algebra 12+ di dalam pembelajaran di Indonesia, pendidik dapat mempertimbangkan melalui faktor-faktor penerimaan terhadap teknologi. Berdasarkan studi terdahulu, maka peneliti menerapkan lima faktor penerimaan siswa terhadap game pembelajaran yaitu Persepsi manfaat penggunaan, Persepsi kemudahan penggunaan, Personal Innovativeness in the Domain of IT (PIIT), sikap dan penerimaan.

Hubungan antar faktor penerimaan pada game pembelajaran DragonBox Algebra 12+ ini dapat dilihat dengan menggunakan Technology Acceptance Model (TAM). TAM merupakan suatu teori yang dapat digunakan sebagai landasan untuk mempelajari dan memahami prilaku user atau pengguna dalam penerimaan dan penggunaan sebuah sistem informasi. Konsep TAM diharapkan dapat membantu memprediksi sikap seseorang dalam penerimaannya terhadap teknologi, serta dapat memberikan informasi yang mendalam mengenai faktor pendorong penerimaan tersebut (van Raaij \& Schepers, 2008).

Berdasarkan penelitian TAM terdahulu (Jap, 2017) mengungkapkan persepsi manfaat penggunaan dan persepsi kemudahan penggunaan menjadi faktor penentu penerimaan game online. Selain itu dari sisi pembelajaran juga ditemukan adanya hubungan yang signifikan dan positif antara kemudahan penggunaan dan manfaat penggunaan dalam penentuan sikap seseorang terhadap penerimaan Virtual Learning Environment (VLE) (van Raaij \& Schepers, 2008). Faktor selanjutnya ialah Personal Innovativeness in the Domain of IT (PIIT) ialah seseorang yang memiliki inovasi akan memiliki minat dan niat dalam pembelian e-book (Shim et al., 2016). Didukung pula dengan pernyataan bahwa PIIT menjadi faktor konsisten yang dapat mempengaruhi hasil penerimaan seseorang terhadap 
teknolog (Lewis et al., 2003).

Sampai saat ini belum ada riset yang mengungkap faktor yang mempengaruhi penerimaan siswa terhadap game pembelajaran matematika DragonBox Algebra 12+. Sehingga perlu dilakukan penelitian lebih lanjut tentang faktor-faktor penerimaan terhadap game pembelajaran matematika DragonBox Algebra 12+ di dalam pembelajaran aljabar. Adapun model atau kerangka kerja pada penelitian ini sebagai berikut :

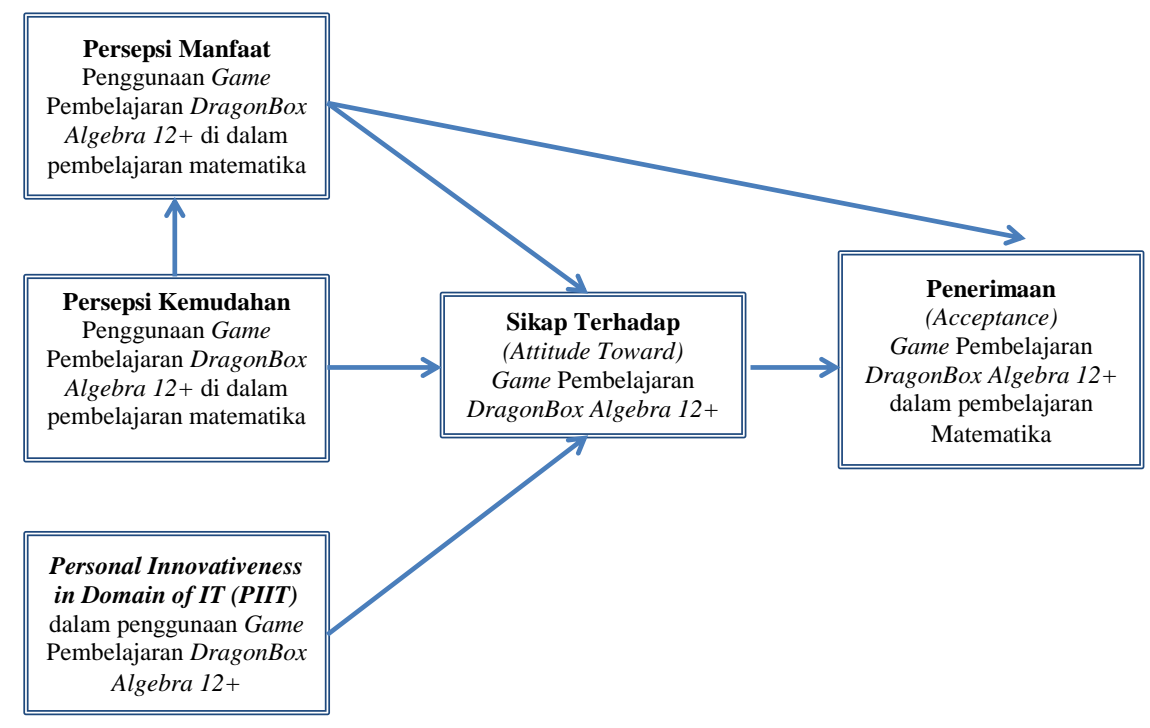

Gambar 1. Model Penelitian untuk Penerimaan DragonBox Algebra 12+

\section{Persepsi Manfaat Penggunaan}

DragonBox Algebra 12+ ini merupakan suatu game pembelajaran yang dapat membantu peserta didik dalam memahami dan menemukan konsep pembelajaran aljabar dengan lebih mudah dan menyenagkan. Jean Baptiste Hyunh yang merupakan pencipta dari DragonBox Algebra 12+ ini dalam situs pribadinya mengklaim bahwa peserta didik yang menggunakan game pembelajaran ini mampu menguasai konsep aljabar hampir 93\% dengan menggunakan permainan selama 1,5 jam. Dibuktikan dengan kemampuan peserta didik dalam menyelesaikan persamaan linier. Sedangkan jika dengan metode pembelajaran konvensional membutuhkan waktu yang lebih lama dan tingkat penguasaan terhadap materi digolong rendah. (Rigopoulos \& Askounis, 2007) mengatakan adanya hubungan yang signifikan dan positif antara manfaat penggunaan dengan actual usage. actual usage merupakan tindakan aktual berupa penggunaan teknologi secara sering dan berulang. Hal ini dapat diartikan sebagai bentuk penerimaan seseorang terhadap penggunaan teknologi. Maka dari itu peneliti memiliki hipotesis ketiga dan keempat sebagai berikut :

H1 : persepsi manfaat penggunaan game pembelajaran DragonBox Algebra $12+$ di dalam pembelajaran matematika memiliki pengaruh positif terhadap sikap siswa dalam penggunaan game pembelajaran DragonBox Algebra 12+ 
H1 : persepsi manfaat penggunaan game pembelajaran DragonBox Algebra $12+$ di dalam pembelajaran matematika memiliki pengaruh positif terhadap penerimaan game pembelajaran DragonBox Algebra 12+ dalam pembelajaran matematika

\section{Personal Innovativeness in the Domain of IT (PIIT)}

Personal innovativeness in the domain of IT (PIIT) merupakan kesediaan seseorang dalam menggunakan teknologi tanpa pengaruh dari orang lain. Inovasi pada penelitian ini berbeda makna nya dengan inovasi yang disampaikan oleh (Rogers, 2003) dalam bukunya Diffution of Inovation. Dimana ia mendefinisikan sebagai perilaku,sedangkan pada konteks ini dimaknai sebagai bentuk keterbukaan seseorang terhadap perubahan. (Agarwal \& Prasad, 1998) merupakan pencetus pertama yang mengembangakan teori difusi inovasi tersebut dalam domain teknologi. Didalam banyak penelitian penerimaan teknoli. Orang yang memiliki inovasi dapat beradaptasi dalam penggunaan teknologi baru (Frambach \& Schillewaert, 2002)

H1 : Personal innovativeness in the domain of IT (PIIT) dalam penggunaan game Pembelajaran DragonBox Algebra $12+$ memiliki pengaruh yang positif terhadap sikap siswa dalam penggunaan game pembelajaran DragonBox Algebra 12+

\section{Attitude Toward DragonBox Algebra 12+}

Attitude dalam Technology Acceptance Model (TAM) merupakan landasan atau dasar dalam mengukur penerimaan menggunakan teknologi yang baru, dengan kata lain dengan melihat attitude dapat melihat bentuk penerimaan ataupun penolakan user terhadap penggunaan teknologi (Davis, 1989). Dalam konteks pendidikan ada banyak studi empiris yang dapat menjelaskan keterkaitan sikap terhadap penerimaan teknologi, beberapa diantaranya ada (Mahande \& Jasruddin, 2016) dalam penelitiannya mengenai penerimaan e-learning mengatakan bahwa sikap atau Attitude memberikan pengaruh yang positif terhadap penerimaan e-learning. Selain itu ada (Hsu et al., 2017) yang juga membuktikan pada penelitiannya terhadap penerimaan e-book. Ia mengungkapkan adanya pengaruh yang positif antara sikap siswa terhadap penerimaan e-book. Mengacu pada teori-teori yang telah dipaparkan diatas, baik dari konteks umum ataupun pendidikan mengatakan adanya pengaruh yang signifikan antara Attitude toward terhadap penerimaan suatu teknologi baru. Sehingga didalam penelitian ini, peneliti memiliki hipotesis keenam yaitu :

H1 : sikap terhadap (Attitude Toward) game pembelajaran DragonBox Algebra $12+$ memiliki pengaruh positif terhadap Penerimaan (Acceptance) geme pembelajaran DragonBox Algebra 12+ dalam pembelajaran matematika

\section{METODE}

Penelitian ini menggunakan metode kuantitatif dengan jenis penelitian yaitu penelitian survey. Desain penelitian pada penelitian ini merupakan penelitian ekplanatif (explanatory). Dimana penelitian ekplanatif adalah penelitian yang memiliki tujuan untuk menemukan penjelasan mengenai 
suatu kejadian ataupun gelajanya. penelitian ekplanatif ini digunakan untuk melihat pola yang memiliki keterkaitan, dengan maksud untuk memperkuat atau membenarkan hipotesa yang telah dibentuk, selain itu mencari sebab akibatkannya, serta meliha sifat yang dibentuk dari hubungan variabel terikat dan variabel bebas di dalam penelitian. Penelitian ini akan menggunakan Technology Acceptance Model (TAM) dengan modifikasi dari penelitian (Lawson-Body et al., 2020). Populasi pada penelitian ini adalah seluruh siswa kelas VII SMP Negeri 7 Kota Jambi. Sedangkan sampel dalam penelitian ini adalah 74 siswa SMP Negeri 7 Kota Jambi yang dipilih secara random sampling. Adapun prosedur pengumpulan data dalam penelitian ini (1) Peneliti memberikan quisioner berupa angket penerimaan game pembelajaran DragonBox Algebra 12+ berdasarkan teori Technology Aceeptance Model (TAM). (2) wawancara untuk mengungkap lebih dalam penerimaan responden terhadap game pembelajaran DragonBox Algebra $12+$ berdasarkan pada factor penerimaan Technology Aceeptance Model (TAM).

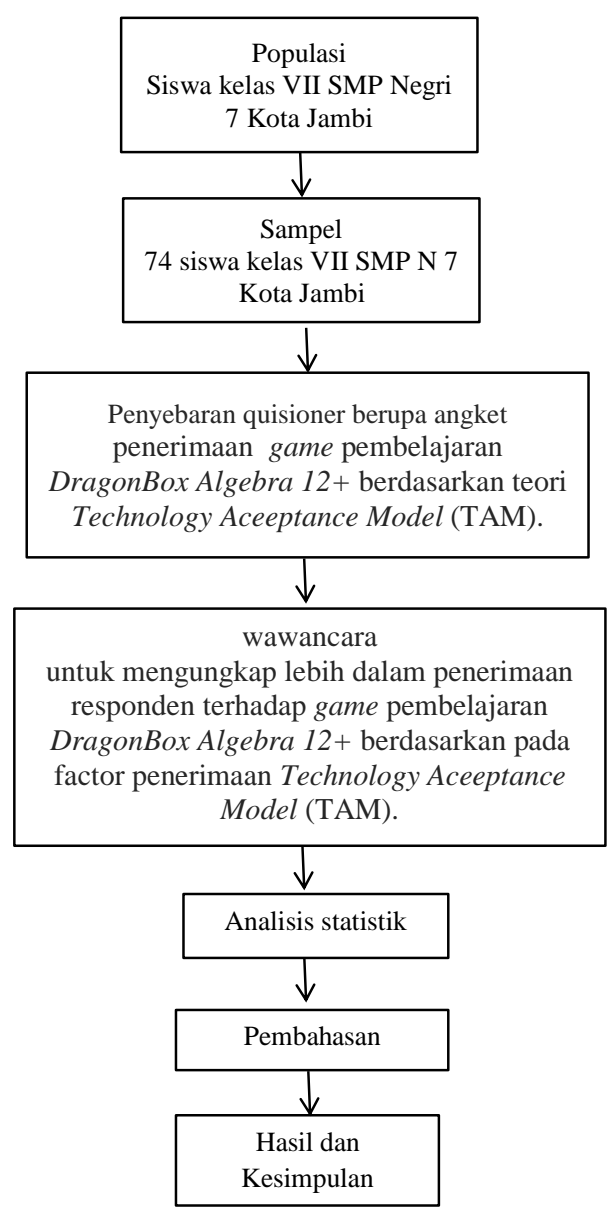

Gambar 2. Prosedur penelitian

\section{Hasil}

\section{Hasil Statistik Deskriptif}

Instrumen dinilai dengan menggunakan skala likert. skor tertinggi 5 pada pernyataan "sangat setuju", sedangkan skor rendah 1 menunjukkan "sangat tidak setuju". 
Tabel 1.

Statistik Deskriptif

\begin{tabular}{|c|c|c|c|c|c|c|}
\hline \multicolumn{7}{|c|}{ Descriptive Statistics } \\
\hline & $\mathrm{N}$ & Minimum & Maximum & Sum & Mean & Std. Deviation \\
\hline Persepsi Manfaat & 74 & 7.00 & 20.00 & 1018.00 & 13.7568 & 3.06912 \\
\hline Kegunaan & & & & & & \\
\hline $\begin{array}{l}\text { Persepsi Kemudahan } \\
\text { Penggunaan }\end{array}$ & 74 & 3.00 & 15.00 & 823.00 & 11.1216 & 2.43239 \\
\hline $\begin{array}{l}\text { Personal Innovativeness in } \\
\text { the domain of IT }\end{array}$ & 74 & 5.00 & 20.00 & 969.00 & 13.0946 & 3.74228 \\
\hline Sikap & 74 & 5.00 & 20.00 & 1045.00 & 14.1216 & 3.35952 \\
\hline Penerimaan & 74 & 7.00 & 20.00 & 1034.00 & 13.9730 & 3.12293 \\
\hline Valid N (listwise) & 74 & & & & & \\
\hline
\end{tabular}

\section{Factor Analysis}

Factor analysis dilakukanuntuk memeriksa estimasi model yang telah di susun berdasarkan beberapa konstruk. Uji estimasi model didalam penelitian ini menggunakan PLS Algorithm pada software smartPLS.

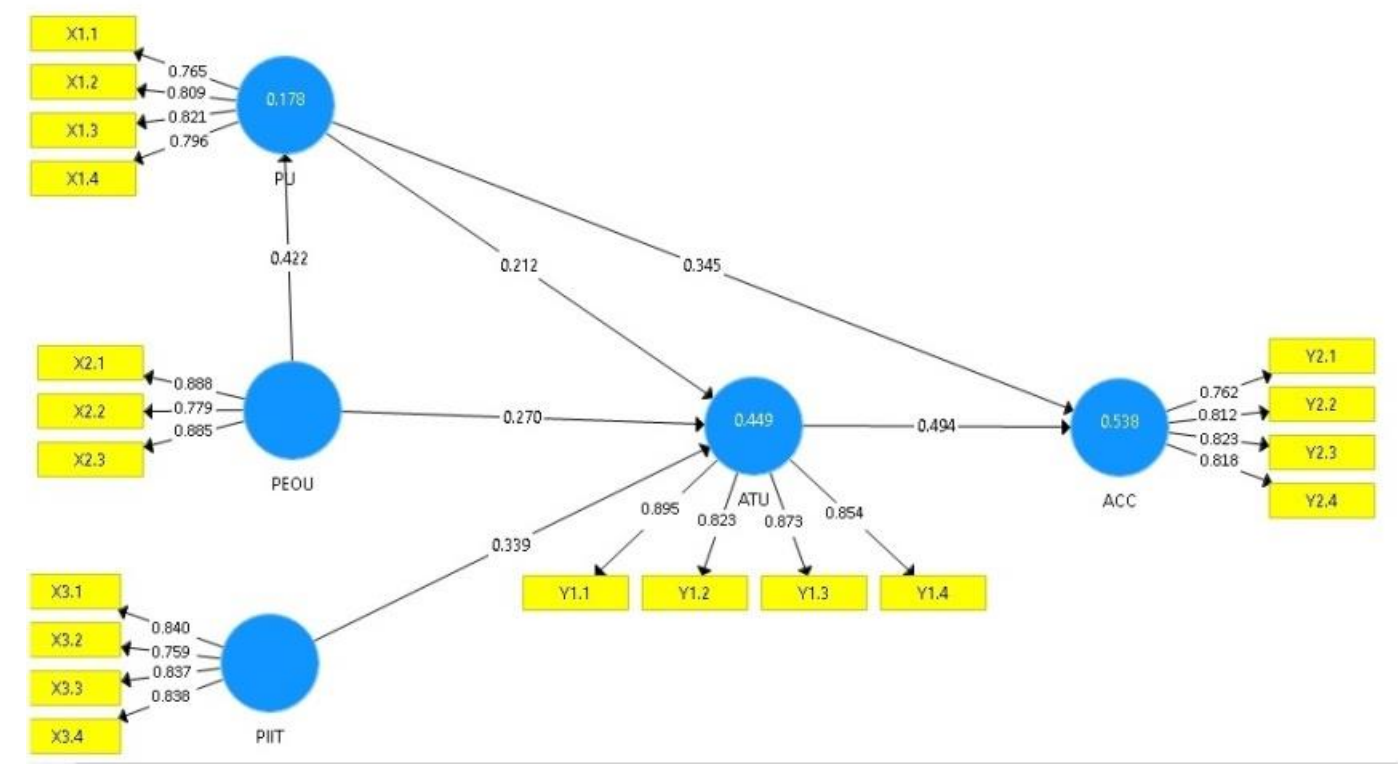

Gambar 3. Estimasi Model

\section{Convergent Validity}

Uji Validitas suatu variable laten terhadap variable indikator-indikator pembentuknya disebut dengan uji unidimensionalitas dapat dilakukan dengan cara melihat convergent validity. Ukuran refleksif individu dapat dikatakan tinggi jika berkorelasi lebih dari 0,7 pada konstruk yang diukur.

Tabel 2.

Output Cross Loading

\begin{tabular}{cccccc}
\hline & $\begin{array}{c}\text { ACC } \\
\text { (Penerimaan) }\end{array}$ & $\begin{array}{c}\text { ATU } \\
\text { (sikap) }\end{array}$ & $\begin{array}{c}\text { PEOU } \\
\text { (Kemudahan } \\
\text { Penggunaan) }\end{array}$ & $\begin{array}{c}\text { PIIT } \\
\text { (Personall } \\
\text { innovativeness in } \\
\text { the domain of IT) }\end{array}$ & $\begin{array}{c}\text { PU } \\
\text { (Persepsi } \\
\text { Manfaat) }\end{array}$ \\
\hline ACC 1 & $\mathbf{0 , 7 6 2}$ & 0,544 & 0,452 & 0,467 & 0,435 \\
ACC 2 & $\mathbf{0 , 8 1 2}$ & 0,593 & 0,373 & 0,603 & 0,540 \\
\hline
\end{tabular}




\begin{tabular}{cccccc}
\hline & $\begin{array}{c}\text { ACC } \\
\text { (Penerimaan) }\end{array}$ & $\begin{array}{c}\text { ATU } \\
\text { (sikap) }\end{array}$ & $\begin{array}{c}\text { PEOU } \\
\text { (Kemudahan } \\
\text { Penggunaan) }\end{array}$ & $\begin{array}{c}\text { PIIT } \\
\text { (Personall } \\
\text { innovativeness in } \\
\text { the domain of IT) }\end{array}$ & $\begin{array}{c}\text { PU } \\
\text { (Persepsi } \\
\text { Manfaat) }\end{array}$ \\
\hline ACC 3 & $\mathbf{0 , 8 2 3}$ & 0,473 & 0,504 & 0,549 & 0,447 \\
ACC 4 & $\mathbf{0 , 8 1 8}$ & 0,535 & 0,465 & 0,475 & 0,492 \\
ATU 1 & 0,589 & $\mathbf{0 , 8 9 5}$ & 0,441 & 0,565 & 0,486 \\
ATU 2 & 0,481 & $\mathbf{0 , 8 2 3}$ & 0,373 & 0,368 & 0,382 \\
ATU 3 & 0,621 & $\mathbf{0 , 8 7 3}$ & 0,516 & 0,562 & 0,449 \\
ATU 4 & 0,597 & $\mathbf{0 , 8 5 4}$ & 0,355 & 0,465 & 0,436 \\
PEOU 1 & 0,518 & 0,414 & $\mathbf{0 , 8 8 8}$ & 0,512 & 0,465 \\
PEOU 2 & 0,444 & 0,555 & $\mathbf{0 , 7 7 9}$ & 0,374 & 0,278 \\
PEOU 3 & 0,445 & 0,381 & $\mathbf{0 , 8 8 5}$ & 0,384 & 0,346 \\
PIIT 1 & 0,531 & 0,524 & 0,321 & $\mathbf{0 , 8 4 0}$ & 0,502 \\
PIIT 2 & 0,469 & 0,306 & 0,396 & $\mathbf{0 , 7 5 9}$ & 0,377 \\
PIIT 3 & 0,568 & 0,437 & 0,423 & $\mathbf{0 , 8 3 7}$ & 0,394 \\
PIIT 4 & 0,564 & 0,579 & 0,399 & $\mathbf{0 , 8 3 8}$ & 0,489 \\
PU 1 & 0,552 & 0,499 & 0,354 & 0,322 & $\mathbf{0 , 7 6 5}$ \\
PU 2 & 0,423 & 0,364 & 0,245 & 0,346 & $\mathbf{0 , 8 0 9}$ \\
PU 3 & 0,420 & 0,292 & 0,367 & 0,502 & $\mathbf{0 , 8 2 1}$ \\
PU 4 & 0,477 & 0,436 & 0,369 & 0,563 & $\mathbf{0 , 7 9 6}$ \\
\hline
\end{tabular}

Berdasarkan hasil loading factor semua indikator untuk masing-masing konstruk sudah memenuhi convergent validity, karena semua nilai loading factor setiap indikator sudah di atas 0,50. Dapat dilihat juga bahwa korelasi masing-masing indikator dengan konstruknya lebih tinggi dari pada dengan konstruk lainnya. Hal ini menunjukan bahwa konstruk laten memprediksi indikator pada bloknya sendiri lebih baik dibandingkan dengan indikator di blok lain.

\section{Discriminant validity}

Discriminant validity adalah dengan membandingkan nilai akar kuadrat dari AVE $(\sqrt{\mathrm{AVE}})$ setiap konstruk dengan nilai korelasi antara konstruk dengan konstruk lainnya (latent variable correlation). Model memiliki nilai discriminant validity yang cukup apabila nilai akar AVE untuk setiap konstruk lebih tinggi daripada nilai latent variable correlation. Output AVE dan latent variable correlation dari PLS Algoritm sebagai berikut :

Tabel 3

Output AVE dan Akar AVE

\begin{tabular}{ccc}
\hline & $\begin{array}{c}\text { Average Variance } \\
\text { Extracted (AVE) }\end{array}$ & $\sqrt{\boldsymbol{A V E}}$ \\
\hline ACC & 0,646 & 0,803741 \\
ATU & 0,742 & 0,861394 \\
PEOU & 0,749 & 0,865448 \\
PIIT & 0,667 & 0,816700 \\
PU & 0,637 & 0,798123
\end{tabular}




\begin{tabular}{cccccc}
\hline & ACC & ATU & PEOU & PIIT & PU \\
\hline ACC & 1,000 & 0,669 & 0,544 & 0,654 & 0,597 \\
ATU & 0,669 & 1,000 & 0,522 & 0,577 & 0,511 \\
PEOU & 0,544 & 0,522 & 1,000 & 0,493 & 0,423 \\
PIIT & 0,654 & 0,577 & 0,493 & 1,000 & 0,543 \\
PU & 0,597 & 0,511 & 0,423 & 0,543 & 1,000 \\
\hline
\end{tabular}

Dapat dilihat bahwa nilai akar AVE setiap konstruk lebih tinggi dibandingkan dengan nilai korelasi setiap konstruk terhadap konstruk lainnya. Jadi dapat disimpulkan bahwa semua konstruk dalam model yang diestimasi memenuhi kriteria discriminant validity. Selain uji validitas konstruk, dilakukan juga uji reliabilitas konstruk yang diukur dengan dua kriteria yaitu composite reliability dan croncbach alpha dari blok indikator yang mengukur konstruk. Konstruk dinyatakan reliabel jika nilai composite reliability dan croncbach alpha di atas 0,70 . Output composite reliability dan croncbach alpha sebagai berikut :

Tabel 4.

Output Composite Reliability

\begin{tabular}{cc}
\hline & Composite Reliability \\
\hline ACC & 0,880 \\
ATU & 0,920 \\
PEOU & 0,899 \\
PIIT & 0,889 \\
PU & 0,875 \\
\hline
\end{tabular}

Tabel 5.

Output Croncbach Alpha

\begin{tabular}{cc}
\hline & Cronbach's Alpha \\
\hline ACC & 0,818 \\
ATU & 0,885 \\
PEOU & 0,832 \\
PIIT & 0,837 \\
PU & 0,811 \\
\hline
\end{tabular}

Output composite reliability dan croncbach alpha di atas menunjukkan bahwa nilai masingmasing konstruk sudah di atas 0,70. Sehingga dapat disimpulkan bahwa masing-masing konstruk dalam model yang diestimasi memiliki reliabilitas yang baik.

\section{Pengujian Hipotesis}

Pengujian hipotesis antar konstruk yaitu konstruk eksogen terhadap konstruk endogen $(\gamma)$ dan konstruk endogen terhadap konstruk endogen $(\beta)$ dilakukan dengan metode resampling bootstrap. Statistik uji yang digunakan adalah statistik $t$ atau uji t. Nilai $t$ pembanding dalam penelitian ini diperoleh dari tabel t. Nilai t-tabel dengan derajat kebebasan (df) sebesar 73 dan taraf signifikansi sebesar 5\% diperoleh sebesar 1,993. 
Tabel 6.

Output Path Coefficients

\begin{tabular}{ccccc}
\hline & $\begin{array}{l}\text { Original } \\
\text { Sample (O) }\end{array}$ & $\begin{array}{l}\text { Sample } \\
\text { Mean (M) }\end{array}$ & $\begin{array}{l}\text { Standard Deviation } \\
(\text { STDEV })\end{array}$ & $\begin{array}{l}\text { T Statistics } \\
(\mid \text { O/STDEV })\end{array}$ \\
\hline PEOU -> ATU & 0,270 & 0,275 & 0,092 & 2,926 \\
PEOU -> PU & 0,422 & 0,429 & 0,095 & 4,451 \\
PU -> ACC & 0,345 & 0,340 & 0,081 & 4,240 \\
PU -> ATU & 0,212 & 0,205 & 0,073 & 2,898 \\
PIIT -> ATU & 0,339 & 0,351 & 0,101 & 3,342 \\
ATU -> ACC & 0,494 & 0,505 & 0,073 & 6,805
\end{tabular}

(1) menunjukkan adanya pengaruh positif antara konstruk PEOU terhadap konstruk PU dengan nilai koefisien sebesar 0,423 dan signifikan pada taraf 5\%. Hal ini dibuktikan dari besarnya nilai $\mathrm{t}$ statistik untuk konstruk PEOU terhadap konstruk PU di atas 1,993 yaitu sebesar 4,384. Jadi dapat disimpulkan bahwa $\mathrm{H} 1$ dapat diterima (2) menunjukkan adanya pengaruh positif antara konstruk PEOU terhadap konstruk ATU dengan nilai koefisien sebesar 0,268 dan signifikan pada taraf 5\%. Hal ini dibuktikan dari besarnya nilai t statistik untuk konstruk PEOU terhadap konstruk ATU di atas 1,993 yaitu sebesar 2,994. Jadi dapat disimpulkan bahwa H1 dapat diterima (3) Hipotesis yang diajukan sebagai Tabel 48 menunjukkan adanya pengaruh positif antara konstruk PU terhadap konstruk ATU dengan nilai koefisien sebesar 0,22 dan signifikan pada taraf 5\%. Hal ini dibuktikan dari besarnya nilai $\mathrm{t}$ statistik untuk konstruk PU terhadap konstruk ATU di atas 1,993 yaitu sebesar 2,835. Jadi dapat disimpulkan bahwa H1 dapat diterima. Pengaruh PU terhadap ACC. (4) Hipotesis yang diajukan sebagai Tabel 49 menunjukkan adanya pengaruh positif antara konstruk PU terhadap konstruk ACC dengan nilai koefisien sebesar 0,221 dan signifikan pada taraf 5\%. Hal ini dibuktikan dari besarnya nilai t statistik untuk konstruk PU terhadap konstruk ATU di atas 1,993 yaitu sebesar 2,406. Jadi dapat disimpulkan bahwa H1 dapat diterima. (5) menunjukkan adanya pengaruh positif antara konstruk PIIT terhadap konstruk ATU dengan nilai koefisien sebesar 0,221 dan signifikan pada taraf 5\%. Hal ini dibuktikan dari besarnya nilai t statistik untuk konstruk PIIT terhadap konstruk ATU di atas 1,993 yaitu sebesar 2,406. Jadi dapat disimpulkan bahwa H1 dapat diterima. (6) menunjukkan adanya pengaruh positif antara konstruk ATU terhadap konstruk ACC dengan nilai koefisien sebesar 0,319 dan signifikan pada taraf 5\%. Hal ini dibuktikan dari besarnya nilai t statistik untuk konstruk ATU terhadap konstruk ACC di atas 1,993 yaitu sebesar 3,856. Jadi dapat disimpulkan bahwa H1 dapat diterima.

Berdaaasarkan wawancara yang telah dilakukan, informasi mengenai kemudahan penggunaan game pembelajaran DragonBox Algebra $12+$ didalam pembelajaran matematika (PEOU) yaitu menurut responden game DragonBox Algebra 12+ ini mudah untuk di operasikan karena game ini lebih sederhana dibandingkan dengan game lainnya oleh karena itu mudah bagi responden untuk menjadi ahli dalam mengoperasikannya. Cara penggunaan nya pun sangat mudah, hanya dengan menggeserkan gambar, atau men-tap gambar dll. Selain itu game DragonBox Algebra 12+ ini di 
dalam pembelajaran aljabar lebih mudah untuk di pahami, karena responden dilatih untuk mendapatkan kosep aljabar berdasarkan langkah demi langkah di dalam permainan, hal ini dapat membantu responden atau siswa untuk memahami konsep bukan menghapal sehingga ilmu yang diperoleh membekas lama diingatan. Responden juga menggunakan game ini diluar jam pembelajaran, walaupun hal ini dilakukan hanya untuk meningkatkan level lebih cepat ketimbang responden yang lain. Hal ini sesuai dengan indikator kemudahan penggunaan game pembelajaran DragonBox Algebra $12+$ yaitu, dapat diterima apabila fleksibel dalam penggunaanya, mudah digunakan dan operasikan, serta mudah untuk dipahami
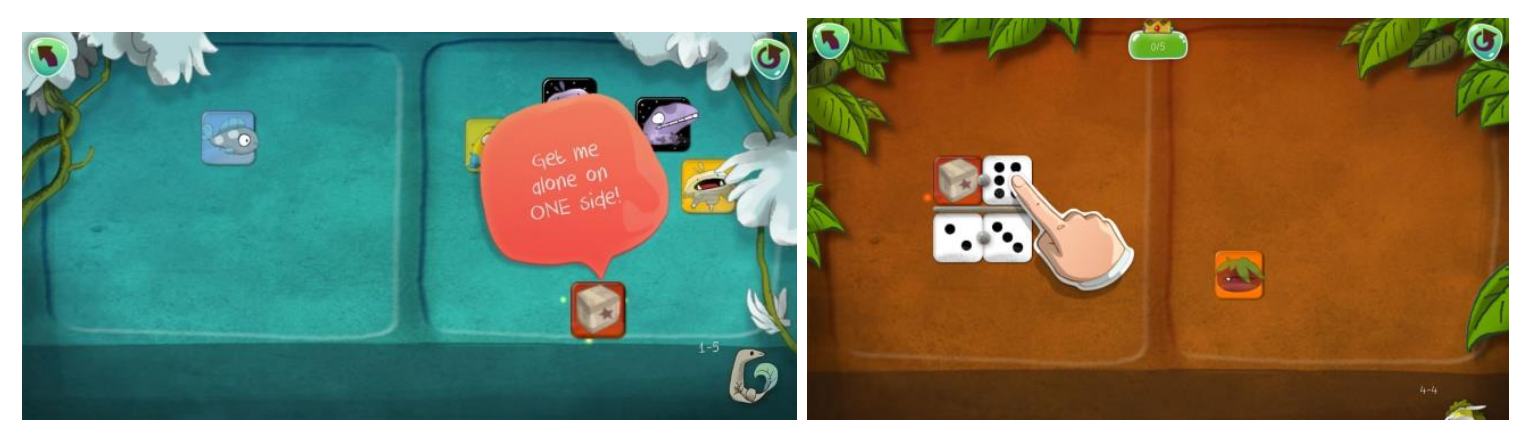

Gambar 4. Visual game DragonBox Algebra 12+

Selain itu game pembelajaran DragonBox Algebra $12+$ ini memiliki manfaat yaitu membuat pembelajaran matematika terasa lebih menyenagkan, responden juga mampu memahami materi aljabar lebih cepat dari pada pembelajaran konvensional. Menurut responden menggunakan game ini membuat belajar yang kaku dapat dilakukan lebih releks dan terasa seperti bermain, game ini mampu memicu rasa ingin tahu yang positif di dalam pembelajaran, dimana pada saat menggunakan game pembelajaran ini responden dapat memperoleh konsep aljabar dari pola permainan. Selain itu selama menggunakan game pembelajaran DragonBox Algebra $12+$ ini membuat responden terbiasa berkompetisi selama pembelajaran. Tujuan dari pembelajaran aljabar ini pun mampu dicapai oleh responden dengan baik, dimana responden berhasil memperoleh nilai yang baik pada ulangan harian. Responden juga mengatakan setelah menggunakan game pembelajaran DragonBox Algebra 12+ ini membuat mereka dapat dengan mudah menyelesikan permasalahan aljabar. Hal ini sesuai dengan indikator manfaat penggunaan game pembelajaran DragonBox Algebra $12+$ yaitu mampu meningkatkan kinerja, produktifitas, efektifitas dan mempercepat pekerjaan di dalam pembelajaran matematika.

Selanjutnya infromasi lebih dalam diperoleh yaitu mengenai personal innovativeness in the domain of IT pada game pembelajaran DragonBox Algebra 12+ didalam pembelajaran matematika (PIIT). Game pembelajaran DragonBox Algebra 12+ baru pertama kali mereka gunakan di dalam proses pembelajaran. Mereka mampu mempengaruhi teman sebaya nya untuk menggunakan teknologi disekolah maupun diluar sekolah. Ketika diminta untuk menjelaskan kembali cara mengoperasikan game DragonBox Algebra 12+ ini kedua responden mampu menjelaskan ulang secara detail kepada 
peneliti cara penyelesaian game tersebut. Hal ini sesuai dengan indikator personal innovativeness in the domain of IT pada game pembelajaran DragonBox Algebra $12+$ didalam pembelajaran matematika (PIIT) yaitu memiliki keinginan, kemauan, kemampuan dan keterampilan dari diri sendiri tanpa ada pengaruh dari orang lain.

Selanjutnya infromasi lebih dalam diperoleh yaitu mengenai Attitude toward atau sikap terhadap game pembelajaran DragonBox Algebra 12+ didalam pembelajaran matematika (ATU). Game pembelajaran DragonBox Algebra 12+ ini mampu membuat pembelajaran matematika menjadi lebih menyengkan, menjadi lebih seru dan mampu menumbuhkan sikap saling bekerja sama dalam menyelesaikan permainan. Kedua responden juga mengatakan bahwa pemilihan game ini merupakan pilihan yang tepat dan bijaksana mengingat matematika merupakan pembelajaran yang cukup ditakuti oleh banyak pelajar. Game pembelajaran DragonBox Algebra 12+ ini pun telah di unduh responden pada ponsel pintar mereka agar bisa terus memainkan nya selain pada pembelajaran di sekolah. Responden pun mengatakan bahwa mereka dapat menerima game pebelajaran DragonBox Algebra $12+$ ini sebagai alat bantu di dalam pembelajaran matematika, dimana setelah menggunakan game ini mereka mampu untuk memenuhi tujuan pembelajaran aljabar. Hal ini sesuai dengan indikator Attitude toward atau sikap terhadap game pembelajaran DragonBox Algebra $12+$ didalam pembelajaran matematika (ATU), yaitu sikap menjadi lebih positif dikarenakan teknologi yang digunakan menyenagkan, teknologi yang digunakan merupakan teknologi yang tepat dan bijaksana dalam penggunaannya, selain itu teknologi juga mampu untuk diterima dengan mudah oleh user.

Selanjutnya infromasi lebih dalam diperoleh yaitu mengenai penerimaan terhadap game pembelajaran DragonBox Algebra 12+ didalam pembelajaran matematika (ACC). menurut hasil wawancara terhadap responden, game pembelajaran DragonBox Algebra 12+ ini membuat responden ingin terus menggunakan game ini dan menyelesaikan semua chapter permainan pada game, mengingat pembelajaran aljabar tidak hanya ada di kelas vii namun juga ada di jenjang selanjutnya. Selain itu responden juga menyampaikan bahwa rata-rata mereka bermain game pembelajaran DragonBox Algebra 12+ ini berkisar antara 1 hingga 2 jam perhari dan juga mereka mampu untuk meberikan dorongan dan rekomendasi kepada teman-teman sepermainan mereka untuk ikut memainkan game pembelejaran DragonBox Algebra 12+ ini. Semua ini mereka lakukan atas dasar kepuasan terhdap game pembelajaran DragonBox Algebra 12+ ini dimana mereka menyampaikan bahwa game ini mampu membuat mereka mencapai tujuan pembelajaran dan juga mempercepat mereka dalam mengetahui informasi terkait konsep dari pembelajaran aljabar.

\section{KESIMPULAN}

Berdasarkan hasil penelitian dan pembahasan yang telah dilakukan, maka dapat disimpulkan: Persepsi kemudahan penggunaan memiliki pengaruh positif terhadap manfaat penggunaan game pembelajaran DragonBox Algebra $12+$ di dalam pembelajaran matematika. Persepsi kemudahan penggunaan memiliki pengaruh positif terhadap sikap siswa terhadap game pembelajaran DragonBox Algebra 12+. 
Persepsi manfaat penggunaan memiliki pengaruh positif terhadap sikap siswa terhadap penggunaan DragonBox Algebra 12+. Persepsi manfaat penggunaan memiliki pengaruh positif terhadap penerimaan game pembelajaran DragonBox Algebra 12+ dalam pembelajaran matematika

Personal innovativeness in the domain of IT (PIIT) memiliki pengaruh yang positif terhadap terhadap sikap yang dibentuk siswa pada game pembelajaran DragonBox Algebra 12+. Sikap terhadap (Attitude Toward) game pembelajaran DragonBox Algebra 12+ memiliki pengaruh positif terhadap Penerimaan (Acceptance) geme pembelajaran DragonBox Algebra 12+ dalam pembelajaran matematika. Peneliti berharap agar sekolah dan guru bidang studi matematika untuk mempertimbangkan menggunakan game ini dalam penyampaian pembelajran materi aljabar di kelas. Dimana game pembelajaran DragonBox Algebra 12+ dianggap oleh siswa SMP Negeri 7 Kota Jambi sebagai game pembelajaran yang bermanfaat dan mudah untuk digunakan.

\section{DAFTAR PUSTAKA}

Agarwal, R., \& Prasad, J. (1998). A Conceptual and Operational Definition of Personal Innovativeness in the Domain of Information Technology. Information Systems Research. https://doi.org/10.1287/isre.9.2.204

Davis, F. D. (1989). Perceived usefulness, perceived ease of use, and user acceptance of information technology. MIS Quarterly: Management Information Systems. https://doi.org/10.2307/249008

Dolonen, J. A., \& Kluge, A. (2015). Algebra learning through digital gaming in school. ComputerSupported Collaborative Learning Conference, CSCL.

Frambach, R. T., \& Schillewaert, N. (2002). Organizational innovation adoption: A multi-level framework of determinants and opportunities for future research. Journal of Business Research. https://doi.org/10.1016/S0148-2963(00)00152-1

Hsu, C. L., Lin, Y. H., Chen, M. C., Chang, K. C., \& Hsieh, A. Y. (2017). Investigating the determinants of e-book adoption. Program. https://doi.org/10.1108/PROG-04-2014-0022

Jap, T. (2017). The Technology Acceptance Model of Online Game in Indonesian Adolescents. Makara Human Behavior Studies in Asia. https://doi.org/10.7454/mssh.v21i1.3497

Lawson-Body, A., Willoughby, L., Lawson-Body, L., \& Tamandja, E. M. (2020). Students' acceptance of E-books: An application of UTAUT. Journal of Computer Information Systems. https://doi.org/10.1080/08874417.2018.1463577

Lewis, W., Agarwal, R., \& Sambamurthy, V. (2003). Sources of influence on beliefs about information technology use: An empirical study of knowledge workers. MIS Quarterly: Management Information Systems. https://doi.org/10.2307/30036552

Mahande, R. D., \& Jasruddin. (2016). pada Program PascasarjanaUTAUT Model : Suatu Pendekatan Evaluasi Penerimaan E-Learning. Prosiding Seminar Nasional.

Rigopoulos, G., \& Askounis, D. (2007). A TAM Framework to Evaluate User's Perception towards Online Electronic Payments. Journal of Internet Banking and Commerce.

Rogers, E. (2003). The Diffusion of Innovations (Fifth Edition). In The Free Press, New York. https://doi.org/10.1007/s10460-007-9072-2

Shim, D., Kim, J. G., \& Altmann, J. (2016). Identifying key drivers and bottlenecks in the adoption of E-book readers in Korea. Telematics and Informatics. https://doi.org/10.1016/j.tele.2015.12.009

Siew, N. M., Geofrey, J., \& Lee, B. N. (2016). Students' Algebraic Thinking and Attitudes towards Algebra: The Effects of Game-Based Learning using Dragonbox $12+$ App. The Research 
Journal of Mathematics and Technology.

van Raaij, E. M., \& Schepers, J. J. L. (2008). The acceptance and use of a virtual learning environment in China Computers and Education. https://doi.org/10.1016/j.compedu.2006.09.001 